This item was submitted to Loughborough's Research Repository by the author.

Items in Figshare are protected by copyright, with all rights reserved, unless otherwise indicated.

\title{
Estimating the potential yield of small building-mounted wind turbines
}

PLEASE CITE THE PUBLISHED VERSION

http://dx.doi.org/10.1002/we.222

\section{PUBLISHER}

(c) John Wiley and Sons Ltd.

\section{VERSION}

AM (Accepted Manuscript)

\section{LICENCE}

CC BY-NC-ND 4.0

\section{REPOSITORY RECORD}

Heath, Malcolm A., John D. Walshe, and Simon J. Watson. 2019. "Estimating the Potential Yield of Small Building-mounted Wind Turbines". figshare. https://hdl.handle.net/2134/17943. 


\title{
Estimating The Potential Yield Of Small Building-Mounted
}

\section{Wind Turbines}

\author{
Malcolm A. Heath ${ }^{\mathrm{a}}$, Simon J. Watson ${ }^{\mathrm{b}, *}$, John D. Walshe \\ ${ }^{a}$ Power Technology, E.ON UK Ltd, Power Technology Centre, Ratcliffe on Soar, Nottingham, NG11 OEE, \\ $U K$ \\ ${ }^{\mathrm{b}}$ Centre for Renewable Energy Systems Technology, Electronic and Electrical Engineering Department, \\ Loughborough University, Ashby Road, Loughborough, LE11 3TU, UK
}

\begin{abstract}
The wind profile in the urban boundary layer is described as following a logarithmic curve above mean building height and an exponential curve below it. By considering the urban landscape to be an array of cubes a method is described for calculating the surface roughness length and displacement height of this profile. Firstly, a Computational Fluid Dynamics (CFD) model employing a k- $\varepsilon$ turbulence model is used to simulate the flow around a cube. The results of this simulation are compared with wind tunnel measurements in order to validate the code. Then the CFD model is used to simulate the wind flow around a simple pitched roof building, using a semi-logarithmic
\end{abstract}

${ }^{*}$ Corresponding author. Tel.: +44-1509-222421; fax: +44-1509-610031.

E-mail address: s.j.watson@lboro.ac.uk (S.J. Watson) 
Potential Yield Of Small Building-Mounted Wind Turbines - Heath et al.

inflow profile. An array of similar pitched-roof houses is modelled using CFD to determine the flow characteristics within an urban area. Mean wind speeds at potential turbine mounting points are studied, and optimum mounting points are identified for different prevailing wind directions. A methodology is proposed for estimating the energy yield of a building mounted turbine from simple information such as a wind atlas wind speed and building density. The energy yield of a small turbine on a hypothetical house in west London is estimated. The energy yield is shown to be very low, particularly if the turbine is mounted below roof top height. It should be stressed that the complexity of modelling such urban environments using such a computational model has limitations and results can only be considered approximate, but nonetheless, gives an indication of expected yields within the built environment.

Keywords: Wind energy, built environment, wind profile, building effects, urban meteorology, computational fluid dynamics

\section{Introduction}

Very little experimental data is available on the flow close to a building. Research has concentrated on the pressure on building walls, not on wind velocity a short distance from the surface. Studies of flow around isolated cubes indicate a 'speed up' effect around the top and sides. This paper uses the CFD model ANSYS CFX to model wind flow around a 'typical' house both in isolation and within an array of similar houses to show the level of speed-up which occurs. 
Potential Yield Of Small Building-Mounted Wind Turbines - Heath et al.

Several manufacturers have recently announced wind turbines aimed at the domestic market, particularly in the UK. These are small machines -1 or 2 metres in diameter intended to be mounted directly on to houses. There is a potentially huge market for these machines, with some people suggesting that the future will see a turbine on every house. However, there has been very little research published on the potential yield of these small machines. Marketing literature typically quotes energy yields assuming a capacity factor of over $30 \%$ which is optimistic even for a carefully planned commercial wind farm consisting of MW-sized machines.

Local councils in the UK have yet to reach a consensus on when to grant planning permission for these machines. At present it is generally much harder to gain permission for work above the ridge of a house than below it. This paper analyses the effect of the precise mounting position of a turbine on its output, in particular showing the importance of being mounted above the ridge line.

Conventional techniques for estimating energy yield involve installing anemometers and measuring wind speeds for up to a year. This is clearly not economically feasible for a domestic machine which may be worth only one or two thousand pounds. Instead a methodology is required which would allow an estimate to be made from a small amount of readily available data. 
Potential Yield Of Small Building-Mounted Wind Turbines - Heath et al.

The problem of calculating energy yield can be split into two halves. Firstly, the mean wind speed in the area around the house must be estimated, and secondly a correction factor must be applied to allow for the local effect of the precise positioning of the turbine.

There is an increasing amount of research into the effect of urban areas on the mean wind profile. Wind tunnel tests have usually simulated towns with an array of cubes or similar obstacles. While this is clearly a huge simplification, it allows a model of wind flow to be developed. Much of this work has been done to look at pedestrian comfort in built-up areas. There has been significant research into the application of Computational Fluid Dynamics (CFD) models for looking at flows around isolated buildings, although work on the simulation of flows around multiple buildings is more limited. The use of Reynolds Averaged Navier Stokes (RANS) solvers employing standard and modified k$\varepsilon$ turbulence closure schemes, as well as Large Eddy Simulation (LES) has been compared for multiple buildings with validation against wind tunnel tests [1], [2], [3]. The simulated model results for wind speed change compare well with the wind tunnel data in all cases, though the prediction of turbulence levels is significantly better when using LES models.

Macdonald [4] has described how the wind profile adopts a vertically displaced logarithmic profile with a large surface roughness length. Grimmond and Oke [5] presented a review of different methods for estimating this displacement height and roughness length from the morphology of surrounding buildings. This paper uses the procedure proposed by Macdonald, Griffiths and Hall [6], which uses relatively simple 
Potential Yield Of Small Building-Mounted Wind Turbines - Heath et al.

data on building heights and densities. This modified logarithmic profile is then used as the inflow condition for the CFD model to simulate the wind flow over buildings in an urban environment.

\section{Mean wind speed profile in an urban area}

When discussing the mean wind profile, it is important to understand that values refer to a temporal and spatial average. Flow patterns, particularly below roof height, are extremely complex, and the wind profile formulae given below do not attempt to predict the speed at a given point. Instead, they give an average speed over an area of a few hundred square meters. 
Potential Yield Of Small Building-Mounted Wind Turbines - Heath et al.

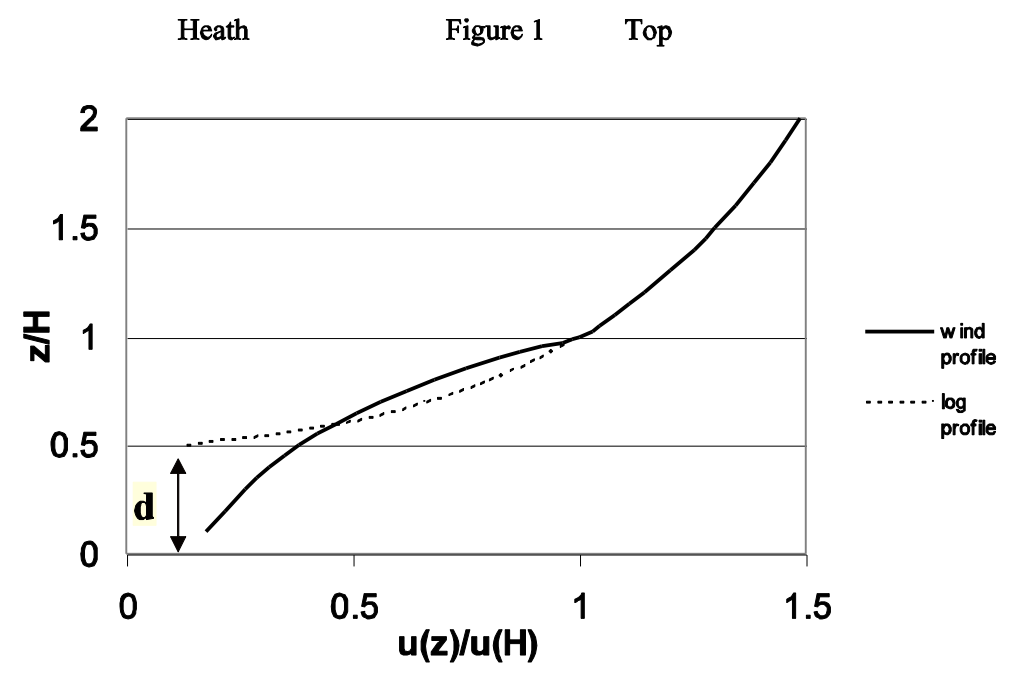

Figure 1 shows the form of the urban wind profile [4]. Above the mean building height $H$, the familiar logarithmic profile is followed, although with a vertical displacement: 
Potential Yield Of Small Building-Mounted Wind Turbines - Heath et al.

$U(z)=\frac{U_{*}}{\kappa} \ln \left(\frac{z-d}{z_{0}}\right)$

where $U *$ is the friction velocity, $d$ is the displacement height, $z_{0}$ is the roughness length and $\kappa$ is the von Kármán constant.

Below the mean building height, wind speed follows an exponential profile:

$U(z)=U_{H} \exp \left(a\left(z / H^{-1}\right)\right)$

where $U_{H}$ is the wind speed at height $H$ as given by the logarithmic profile, and $a$ is a constant which is dependant on building morphology. Macdonald states that for an array of cubes, $a$ can be approximated to $a=9.6 \lambda_{f}$. The frontal area density, $\lambda_{f}$, is a measure of how built up an area is. For a given area of land, it is defined as the total frontal surface area of buildings (as seen by the wind), divided by the total land area.

This exponential curve fails to meet the no slip principle, as it does not have zero velocity at zero height. However, this paper is mostly concerned with wind speeds around roof top height, so this problem can be ignored.

The surface roughness length $z_{0}$, and displacement height $d$, as used by the logarithmic profile, can be estimated from building morphology [6]:

$$
\frac{z_{0}}{H}=\left(1-\frac{d}{H}\right) \exp \left[-\left(0.5 \beta \frac{C_{D}}{\kappa^{2}}\left(1-\frac{d}{H}\right) \lambda_{f}\right)^{-0.5}\right]
$$


Potential Yield Of Small Building-Mounted Wind Turbines - Heath et al.

$$
\frac{d}{H}=1+A^{-\lambda_{p}}\left(\lambda_{p}-1\right)
$$

where $\lambda_{f}$ and $\lambda_{p}$ are the frontal and plan area densities respectively, $C_{D}$ is the drag coefficient of the buildings, $A$ is a constant determined by the arrangement of buildings, and $\beta$ is a correction factor for building drag. Values of $A=4.4, \beta=0.55$ and $C_{D}=1.2$ are suggested for a staggered array of cubes [6].

Typical suburban housing estates have building densities of around $20 \%$. As an approximation, and in the absence of any more accurate data, houses can be considered to be arranged in a staggered array. For example, consider a housing estate with a staggered array of $10 \mathrm{~m}$ high cubic buildings, with plan and frontal area densities of $20 \%$. These formulae give a roughness length of $0.8 \mathrm{~m}$ and a displacement height of $3.9 \mathrm{~m}$. In the UK, their exists a wind atlas of estimated wind speed values on a $1 \mathrm{~km}$ grid at three heights above the ground [7] produced using the NOABL mass-consistent model [8] where a uniform roughness length of $0.03 \mathrm{~m}$ and zero displacement height have been assumed. This database is being increasingly used for estimating the likely resource in urban areas. It can be seen that with such contrasting roughness lengths and displacements heights that this wind atlas will be over estimating the wind speed in an urban area. This will be particularly true at low heights, for example at the roof top, when the displacement height will be very significant.

It should be noted that the approach to modelling the urban wind speed profile mentioned above takes no account of vegetation. This was done due to the complexity of estimating the effect of individual trees, hedges and bushes in an urban area. In 
Potential Yield Of Small Building-Mounted Wind Turbines - Heath et al.

addition this give a very large array of configurations that it would not be feasible to simulate. In areas of low building density the effect of trees, bushes, etc, is likely to be significant as much of the space between houses will be filled with plants and trees. The roughness length is therefore likely to be higher in reality than is estimated here.

\section{Finding a reference wind speed from the wind atlas}

In order to apply the above wind profile formulae in a particular location, if the friction velocity is not known, a reference wind speed at a reference height must be established. Assuming anemometer measurements are not available, the UK NOABL-derived wind atlas can be used as a starting point.

To convert the wind atlas speed into a local reference speed, Mertens [9] suggests treating the edge of the urban area as a step change in roughness. Upwind of the urban boundary, the wind has a speed at height $z_{A}$ of $U_{A}\left(z_{A}\right)$, as given in the atlas, and a profile determined by a surface roughness length $z_{0 A}$ of $0.03 \mathrm{~m}$. Downwind of the boundary the wind is considered to have a profile determined by $z_{0}$ and $d$ as calculated in the previous section. Knowing the distance $x$ to the urban boundary, it is possible to apply the formulae of Taylor and Lee [10], modified to include the displacement height, to calculate the wind speed $U(z)$ at a height $z$ :

$$
U(z)=\frac{\ln \frac{(z-d)}{z_{0}}}{\ln \frac{\left(\delta_{1}-d\right)}{z_{0}}} \cdot \frac{\ln \frac{\delta_{1}}{z_{0 A}}}{\ln \frac{z_{A}}{z_{0 A}}} U_{A}\left(z_{A}\right)
$$

where the internal boundary layer height $\delta_{1}$ is given by: 
Potential Yield Of Small Building-Mounted Wind Turbines - Heath et al.

$$
\delta_{1}=0.75 z_{0}\left(\frac{x}{z_{0}}\right)^{0.8}
$$

Figure 2 shows how the mean wind speed at a given height changes as the distance from the urban boundary increases. Once $x>1000 \mathrm{~m}$, there is no significant change in $U$, so the distance $x$ need only be measured very approximately if we are interested in a point which is not close to the edge of an urban area.

\section{The CFD Model}

Domestic wind turbines are designed to be mounted close to the building. Most manufacturers suggest a maximum mast length of $3 \mathrm{~m}$. This implies that the wind flow will be strongly influenced by the building. CFD modelling is used here to determine the effects of the building at points where a turbine might be mounted.

The CFD simulations were performed using ANSYS CFX 10. The default equations solved by ANSYS CFX are formulated in the flux form. These are the standard averaged equations used in fluid mechanics:

Continuity equation:

$$
\frac{\partial \rho}{\partial t}+\frac{\partial\left(\rho U_{i}\right)}{\partial x_{i}}=0
$$


Potential Yield Of Small Building-Mounted Wind Turbines - Heath et al.

$$
\frac{\partial\left(\rho U_{i}\right)}{\partial t}+\frac{\partial\left(\rho U_{i} U_{j}\right)}{\partial x_{j}}=F_{i}+\frac{\partial \sigma_{i j}}{\partial x_{j}}
$$

with

$$
\sigma_{i j}=-p^{\prime} \delta_{i j}+\mu_{e f f}\left(\frac{\partial U_{i}}{\partial x_{j}}+\frac{\partial U_{j}}{\partial x_{i}}\right)
$$

$U_{i}$ are the mean velocities in the coordinate directions $x_{i}, F_{i}$ stands for the body force vector acting on the fluid parcel (e.g. Coriolis or buoyancy force) and $\mu_{e f f}=\mu+\mu_{T}$ is the effective fluid viscosity which, with the adoption of an eddy-viscosity model, is the sum of the molecular viscosity $\mu$ and turbulent viscosity $\mu_{T}$. The value of $p^{\prime}$ is given by:

$$
p^{\prime}=p+\frac{2}{3} \rho k+\frac{2}{3} \mu_{e f f} \frac{\partial U_{i}}{\partial x_{i}}-\rho \vec{g} \cdot \vec{x}
$$

which gives the total fluid pressure $p$ plus contributions associated with the turbulent kinetic energy $k$ and flow divergence. When the gravity vector is considered in the simulation, the hydrostatic contribution is removed from $p$.

Various turbulence closures are available within the standard version of ANSYS CFX. Here we use the standard $k-\varepsilon$ model [11], with two conservation equations for the turbulent kinetic energy $k$ and turbulent dissipation rate $\varepsilon$ : 
Potential Yield Of Small Building-Mounted Wind Turbines - Heath et al.

$$
\begin{aligned}
& \frac{\partial(\rho k)}{\partial t}+\frac{\partial\left(\rho k U_{i}\right)}{\partial x_{i}}=\frac{\partial}{\partial x_{i}}\left[\left(\mu+\frac{\mu_{T}}{\sigma_{k}}\right) \frac{\partial k}{\partial x_{i}}\right]+P+G-\rho \varepsilon \\
& \frac{\partial(\rho \varepsilon)}{\partial t}+\frac{\partial\left(\rho \varepsilon U_{i}\right)}{\partial x_{i}}=\frac{\partial}{\partial x_{i}}\left[\left(\mu+\frac{\mu_{T}}{\sigma_{\varepsilon}}\right) \frac{\partial \varepsilon}{\partial x_{i}}\right]+C_{1} \frac{\varepsilon}{k}\left(P+C_{3} \max (G, 0)\right)-C_{2} \rho \frac{\varepsilon^{2}}{k}
\end{aligned}
$$

with the shear production term:

$$
P=\mu_{e f f} \frac{\partial U_{i}}{\partial x_{j}}\left(\frac{\partial U_{i}}{\partial x_{j}}+\frac{\partial U_{j}}{\partial x_{i}}\right)-\frac{2}{3} \frac{\partial U_{j}}{\partial x_{j}}\left(\rho k+\mu_{e f f} \frac{\partial U_{l}}{\partial x_{l}}\right)
$$

the buoyancy production term:

$$
G=-\frac{\mu_{e f f}}{\rho \sigma_{H}} \vec{g} \vec{\nabla} \rho
$$

and the turbulent viscosity:

$$
\mu_{T}=C_{\mu} \rho \frac{k^{2}}{\varepsilon}
$$

The default values for the turbulence model constants are $C_{1}=1.44, C_{2}=1.92, C_{3}=0$, $C_{\mu}=0.09$, and $\sigma_{\varepsilon}=0.7179, \sigma_{k}=1, \sigma_{H}=0.9$.

ANSYS CFX is based on a coupled solver for mass and momentum and uses an algebraic multi-grid algorithm for convergence acceleration. The numerical scheme is a 
Potential Yield Of Small Building-Mounted Wind Turbines - Heath et al.

co-located pressure based method for all Mach numbers. A Rhie-Chow interpolation scheme [12] is used to locate the solution of the pressure and velocity fields at the same nodal locations in the mesh.

Due to the impracticality of modelling the turbulent structure close to the ground, wall functions have been used to model the mean wind profile and turbulent kinetic energy.

\section{Test Case: Flow Around a Cube}

In order to assess how accurate CFX is in simulating flow around obstacles, a test case was run to model the flow around a cube in a channel. The results of the simulation were then compared with the well-known wind tunnel measurements made by Martinuzzi and Tropea [13]. Martinuzzi and Tropea looked at a number of obstacles in a wind tunnel including a $2.5 \mathrm{~cm}$ cube which we chose to simulate here. Pressure measurements around the cube were made and the flow around the cube visualised using crystal violet, oil-film and laser-sheet techniques.

The CFX simulation domain was set up in a similar way to the wind tunnel configuration used in [13] and the cube was meshed using a $0.3 \mathrm{~cm}$ cell edge length with a $1 \mathrm{~mm}$ prismatic inflation layer. The wind flow through the channel was set to give a Reynolds number (Re) of $10^{5}$ as reported in [13].

Figure 3 shows the resulting flow pattern around the cube from the CFD simulation as seen from above at $0.2 \mathrm{~cm}$ above the ground level. This pattern broadly agrees with [13] 
Potential Yield Of Small Building-Mounted Wind Turbines - Heath et al.

in that a 'horse-shoe' vortex is seen immediately upstream of the cube. The start of this vortex is marked by a separation point, which the simulation gives at $0.5 H$ upstream of the cube where $H$ is the height of the cube $(2.5 \mathrm{~cm})$. This is very close to that seen by Martinuzzi and Tropea. Immediately downstream of the cube, can be seen two areas of circulation and there is evidence that the flow is unsteady as these vortices are not symmetric. It should be noted that the results shown in Figure 3 are those which result at the point at which there is convergence and no effort has been made to time average these vortices. The main aim was to see how far the CFD simulation was able to reproduce the flow structures seen in a wind tunnel. These two vortices are also seen in the wind tunnel data. Further downstream of the cube, the flow reattaches. This is around $3 \mathrm{H}$ in the simulation. The data in [13] suggest reattachment at about $1.7 \mathrm{H}$ downstream. This discrepancy might have been expected as it is known Navier-Stokes models that use a k- $\varepsilon$ turbulence model tend to predict a reattachment distance which is too large.

Figure 4 shows a comparison of the pressure coefficient $\mathrm{Cp}$ upstream of the cube predicted by CFX and measured by Martinuzzi and Tropea. Here, the coordinate $x$ refers to the direction upstream and $z$ refers to the direction across wind of the cube which is the convention used in [13]. Elsewhere in this paper, we use $z$ to refer to the height above ground. The pressure coefficient, $\mathrm{Cp}$ is defined as:

$$
C_{p}=\frac{P-P_{a t m}}{\frac{1}{2} \rho U^{2}}
$$

Where $P$ is the pressure measured at the point in question, $P_{\text {atm }}$ is the mean atmospheric pressure, $\rho$ is the density of air and $U$ is the characteristic velocity. The precise value of the characteristic velocity used in [13] to calculate the values in Eq. 16 is unclear, 
Potential Yield Of Small Building-Mounted Wind Turbines - Heath et al.

however, the channel bulk velocity referred to by the authors is likely to be close to this. The characteristic velocity may be slightly higher than this as the wind profile will have a peak value in the centre of the flow which is slightly higher than at the walls due to wall friction. A value of the characteristic velocity $10 \%$ higher than the bulk velocity was used to calculate the values predicted by CFX in Figure 4. This was slightly arbitrary but gives a reasonable fit to the data and at least shows that the mean trend predicted by CFX is quite close to the wind tunnel observations.

Figure 5 shows a comparison of the Cp value around the cube predicted by CFX and measured in the wind tunnel by Martinuzzi and Tropea. It can be seen that the flow predicted around the cube immediately upstream is in reasonable agreement with the wind tunnel data. However, downstream of the windward face of the cube, there is some deviation between the CFD results and the wind tunnel measurements. The CFD model seems to under-predict the maximum pressure drop and the pressure recovery predicted is slower than actually seen from the wind tunnel measurements. This broadly agrees with the comments made above about the limitations of the $\mathrm{k}-\varepsilon$ turbulence model.

In conclusion, this test case shows that the CFD model is able to predict the flow quite well immediately upstream of an obstacle, and the pattern of flow predicted around the obstacle is broadly correct, but downstream there will be some degree of error using the $\mathrm{k}-\varepsilon$ turbulence model. 
Potential Yield Of Small Building-Mounted Wind Turbines - Heath et al.

\section{The Building Layout}

Every building is different and the wind flow around it is affected by many factors, from its shape and size to the positioning of chimneys and dormer windows. Only a very simple building has been modelled here, but it is enough to demonstrate certain effects.

The model, shown in Figure 6, is of a simple pitched roof house. It is $10 \mathrm{~m} \times 10 \mathrm{~m} \times$ $10 \mathrm{~m}$, with a $45^{\circ}$ pitched roof. This is roughly the equivalent of a two-storey building.

The semi-log wind profile described above is intended to represent the wind flowing through an urban area. However, it is a spatial average and should not be used to predict the instantaneous wind speed at a given point. Therefore, it is not adequate to simply model a single building with this profile for the inflow wind. Neighbouring buildings must be included in the model. A simplified version of a suburban neighbourhood has been modelled here, with houses arranged in a staggered array in a street like manner, as shown in Figure 7. Ground in between buildings was modelled with a surface roughness length of $0.001 \mathrm{~m}$, appropriate for a surface such as well mown grass, concrete or tarmac. Though it could be argued that a large value, e.g. $0.03 \mathrm{~m}$ should be used to simulate surrounding fields, this lower value was chosen to simulate the effect of the wind fetch coming over a tarmac or concrete area that might well surround a housing estate. The array of houses was rotated between runs, to simulate wind flow from different directions. 
Potential Yield Of Small Building-Mounted Wind Turbines - Heath et al.

An unstructured tetrahedral mesh was used with an inflation or extruded prism layer close to the walls. The top and sides of the domain were given a free slip boundary condition whereby the shear stress is set to zero so that the fluid is not retarded, the velocity normal to the wall is set to zero and the velocity parallel to the wall is calculated during the solution. The size of the domain was made large enough to ensure that the domain walls did not significantly influence the flow solution. The horizontal width of the domain varied accordingly. There was a $20 \mathrm{~m}$ distance between the inlet and the most upwind building. The domain had a height of $60 \mathrm{~m}$. The walls and roofs of the buildings were considered to be smooth walls. A sensitivity study was carried out to examine how the flow field changed with changing mesh resolution. It was found that a tetrahedral mesh with a default body spacing of $8 \mathrm{~m}$ throughout the volume, reducing to a face spacing of $4 \mathrm{~m}$ at the ground and $0.7 \mathrm{~m}$ at the building walls gave a reasonably convergent result and the solution did not change significantly using a resolution finer than this.

\section{Inflow Wind Profile}

The inflow wind was modelled with the semi-log wind profile described above. It should be noted that a number of assumptions and approximations have been made which inevitably will mean that the profile incident on the row of houses will not be that seen in reality, but nonetheless gives something which is more appropriate than the simple logarithmic profile and at least has some justification in an urban environment. A reference wind speed $U_{0}$ of $10 \mathrm{~m} / \mathrm{s}$ at $10 \mathrm{~m}$ (roof top height) was chosen. The simulation had a very high Reynolds number, so wind behaviour would be the same at any reasonable wind speed. 
Potential Yield Of Small Building-Mounted Wind Turbines - Heath et al.

The model suburban neighbourhood had plan and frontal area densities of $22 \%$. This gave values of $z_{0}=0.8 \mathrm{~m}, d=4.3 \mathrm{~m}$ and $a=2.1$. A turbulence intensity of $10 \%$ was used.

The simulation was run three times, with the wind from three different directions. Treating Figure 7 as a map, these were from the West, North West, and North. Rules of symmetry can be applied to infer results from the other compass points.

\section{Analysis of the CFD Results}

ANSYS CFX produced converged output data every 0.5 seconds for 10 seconds to simulate any unsteady flow characteristics. These data were averaged together to give a mean wind flow within the array of houses.

The results presented show the magnitude of the wind velocity, as opposed to simply the $U$ component. This allows calculation of the maximum energy potential of the wind. It can be assumed that turbines would be able to yaw freely, allowing both $U$ and $V$ components to be utilised. Different turbine designs respond differently to pitched wind flow, however the $W$ component of the wind was not found to be large, so these differences are unlikely to be very significant. In reality, of course, a small buildingmounted wind turbine is unlikely to follow the frequent changes in wind direction exactly resulting in a degree of yaw error. This means the yields presented later in this paper will tend to be an over-estimate of actual performance. 
Potential Yield Of Small Building-Mounted Wind Turbines - Heath et al.

All results have been normalised. Heights are given relative to the mean building height $H(10 \mathrm{~m})$, and wind speeds relative to the upstream velocity at height $H, U_{0}(10 \mathrm{~m} / \mathrm{s})$.

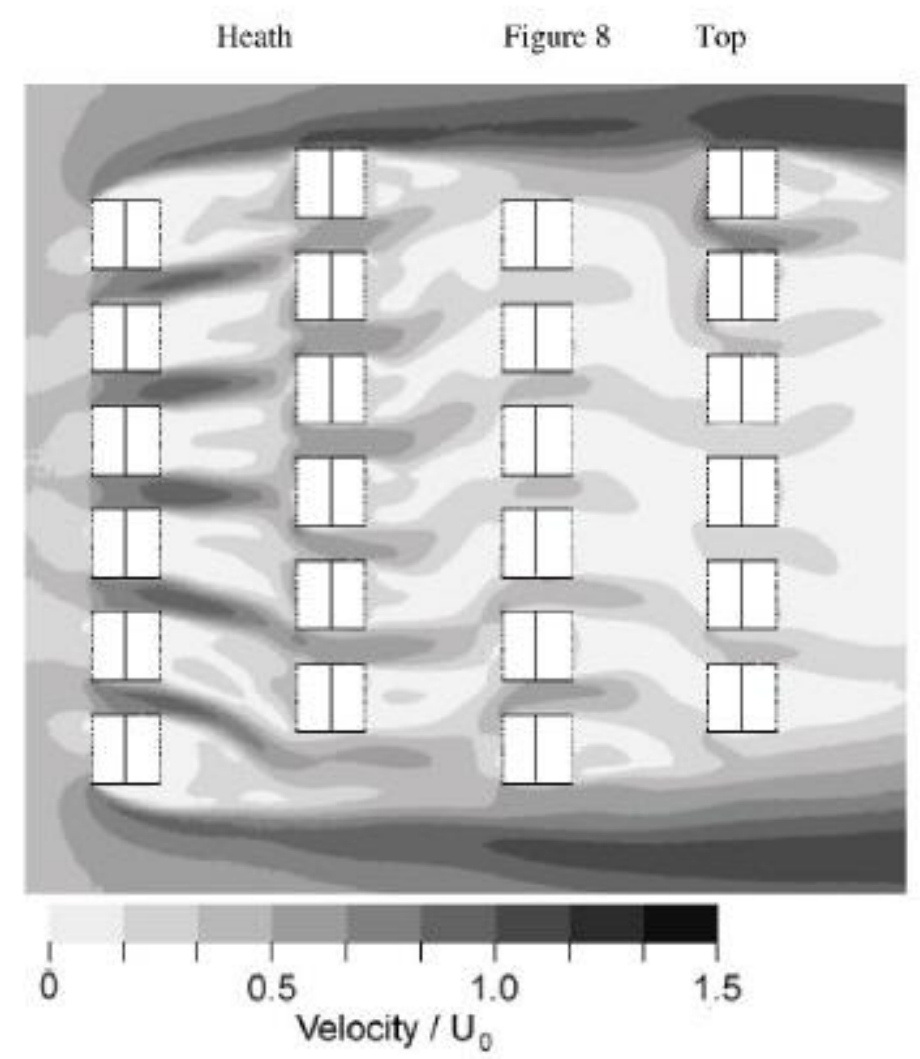

General flow pattern

Figure 8 shows the adjustment of a westerly wind as it flows through the building array. There is a general decrease in velocity as the wind crosses the rows of houses. This suggests that the inflow wind profile has not been calculated correctly. If it were, the spatial mean wind velocity should not change as it moves through the array. This is not surprising, as the profile was calculated assuming a regular array of cubes. In addition, the first row of houses may be affecting the inflow profile to some degree. Different values of $A, C_{D}$ and $\beta$ should be used to match this street like arrangement of houses. However, there are no great differences between the third and fourth rows, so the wind flow can be considered to be fully adjusted by the fourth row. In [3], three different arrays of buildings were simulated and compared with wind tunnel data. Although none 
Potential Yield Of Small Building-Mounted Wind Turbines - Heath et al.

of the building arrays are identical to the array in this work, they are similar and the magnitude of wind speed changes around the buildings is broadly similar to that seen here, with the exception that the general decrease across the array from inlet to outlet is not so pronounced confirming the remarks made above. As [2] suggests that both RANS CFD models with k- $\varepsilon$ and LES models give good predictions of the wind speed changes around buildings and we are not concerned with turbulence levels, then we can be reasonably confident that our results are accurate enough for assessing small wind turbine yield within a housing array, at the same time bearing in mind the limitations highlighted by the cube test case.

Some slight increase in wind speed can be seen as the wind is forced between buildings. The wake patterns behind the houses, which on average are directed downwind, appear to snake north and south. This is probably caused by the asymmetry in the length of the rows of houses.

The rest of the results presented here will concentrate on wind flow around the building in the middle of the most downwind row of houses. Exactly which building this is will vary depending on the wind direction. Figure 9 shows the flow of a westerly wind across the house. It can be seen that the velocity is generally much lower than upstream of the buildings. Below roof height, the velocity is very low, and there is a large, slow, area of recirculation downstream of the house. Higher up, the velocity decreases as the wind approaches the house. It increases very slightly as it crosses the ridge and then slows again. 
Potential Yield Of Small Building-Mounted Wind Turbines - Heath et al.

This should be contrasted with the flow across an isolated building, as shown in Figure 10. This was modelled with an inflow wind profile with a roughness length of $0.001 \mathrm{~m}$, and no vertical displacement. It shows a much more pronounced speed up effect as the wind passes over the ridge. It is significant that this speed-up effect is virtually absent from a house within an urban environment.

\section{Wind speed at potential turbine locations}

This paper is particularly interested in the wind speed at potential mounting points for turbines. These are the corners, the middle of walls, and the centre of the roof, as shown in Figure 11. Each point is $0.5 \mathrm{~m}$ away from the wall, to allow room for mounting brackets, etc. Of course, if the turbine were mounted below roof height, it would have to be further from the wall than this to allow space for it to rotate.

The hub height of a turbine is likely to be very significant in determining its performance. Figure 12 (a) to (d) shows the variation of wind speed with height at each location (only the four main compass points N, E, S and W are shown for clarity). This figure shows that the wind is very strongly sheared around roof top height, at all the possible mounting positions. Even small increases in the turbine hub height will have large effects on the mean wind speed, and hence the generated power. All locations, even the centre of the house, show considerable variation in output with wind direction.

Figure 13 shows a comparison of the mean wind speeds over all directions at each location. This averaging of speeds is only valid in areas with an evenly distributed wind rose, but it shows that in such areas the turbine location is not important, when it is 
Potential Yield Of Small Building-Mounted Wind Turbines - Heath et al.

above roof height. Below roof height the gable ends perform badly compared to the other locations.

It is useful at this point to define a new parameter, the local effect coefficient, $l$. This is the ratio of the wind velocity at a given point to the mean velocity at mean building height, $U_{0}$. The value of $l$ will vary with the wind direction and height.

In areas with a strongly prevailing wind direction, the optimum mounting position is likely to be different to that for a wind rose where the probability of wind blowing from a particular direction is equal. Table 1 shows the optimum location for each wind direction, and its value for the local effect coefficient. It must be remembered that this applies to streets aligned in a north - south direction. An offset in the alignment could be considered as giving the same offset to the prevailing wind.

It is worth emphasising that these results apply only to the specific house and layout modelled here. It is impossible to say whether any of these recommendations for optimum mounting positions, or values of $l$, can be applied more generally.

In the real world there would be practical restrictions on where a turbine could be mounted. The mast may have a maximum length of $3 \mathrm{~m}$. On our house with $5 \mathrm{~m}$ high walls this would mean that turbines mounted at the corners or front of the house would have a maximum hub height of $8 \mathrm{~m}$. Planning permission restrictions may mean that the turbine blades cannot reach above the height of the roof ridge. With a rotor diameter of 
Potential Yield Of Small Building-Mounted Wind Turbines - Heath et al.

$2 \mathrm{~m}$, this would mean a maximum hub height of $9 \mathrm{~m}$ to stay below the $10 \mathrm{~m}$ high ridge. Table 2 gives the optimum turbine locations under these limitations.

\section{Case Study}

It is now possible to calculate the estimated energy yield of a turbine mounted on the house previously modelled. The house will be located in a hypothetical area of west London, with the UK Ordnance Survey map reference TQ1277. It shall be assumed that the area has the same street layout as the model. It is also assumed that the surrounding city is homogenous, with buildings having frontal and plan densities of $22 \%$, and a mean height of $10 \mathrm{~m}$. A hypothetical turbine is assumed to be installed on the house, chosen to be the Swift by Renewable Devices. This is a $1.5 \mathrm{~kW}$ rated machine with a $2 \mathrm{~m}$ rotor diameter. The simplest form of the calculation would deal only with the mean wind speed. However, wind rose information for west London is available from the meteorological station at Heathrow airport [14], so a more detailed calculation is performed that takes the wind rose into account.

First, the mounting point for the turbine must be decided. It shall be assumed that the maximum mast length is $3 \mathrm{~m}$, but that there are no planning restrictions on the location of the turbine. The wind rose shows that the prevailing wind is from the South West, so from Table 2 it can be seen that the optimum mounting point would be $3 \mathrm{~m}$ above the North gable end.

To begin the calculation, an estimated value of the wind speed at $10 \mathrm{~m}$ above the ground is taken from the UK wind atlas at the map reference. This gives a mean wind speed at 
Potential Yield Of Small Building-Mounted Wind Turbines - Heath et al.

$10 \mathrm{~m}$ reference height of: $U_{A}=4.9 \mathrm{~m} / \mathrm{s}$. The calculation must now consider each segment of the wind rose in turn, starting with the North wind, from $337.5^{\circ}$ to $22.5^{\circ}$. The wind atlas wind speed must be converted into a local mean wind speed that considers the effect of urban roughness. The local surface roughness length and displacement height can be calculated using Eqs. 3 and 4 , giving values of $z_{0}=0.8 \mathrm{~m}$ and $d=4.3 \mathrm{~m}$. The distance to the edge of the city in a northerly distance can be measured from a map giving $x=28000 \mathrm{~m}$. Eq. 5 now allows a calculation of the mean northerly wind speed at the roof top height $z=10 \mathrm{~m}$. This gives a value of $U_{0}=2.3 \mathrm{~m} / \mathrm{s}$. The mean wind speed must be adjusted for the local effect of a North wind at the mounting point using the local effect parameter for a northerly wind, $l_{n}=1.2$. This gives a mean adjusted wind speed of $\bar{U}=l_{n} \times U_{0}=2.8 \mathrm{~m} / \mathrm{s}$.

To calculate the energy yield of the turbine, the wind speed is assumed to be distributed with a Rayleigh distribution. This is combined with the power curve of the turbine[15] and the percentage frequency of a North wind from the wind rose. The average annual energy yield from the North wind is thus: $E$ (north) $=79 \mathrm{kWh}$.

This process must now be repeated for every segment of the wind rose. The results are summarised in Table 3. The mean annual energy yield will be $520 \mathrm{kWh}$ which corresponds to a capacity factor of around $4 \%$.

This calculation has been repeated with the planning constraint that rotor blades may not pass above the height of the roof ridge. In this situation, the optimum mounting point is on a $3 \mathrm{~m}$ mast above the North West corner of the house. The average annual 
Potential Yield Of Small Building-Mounted Wind Turbines - Heath et al.

yield is now only $108 \mathrm{kWh}$. Clearly it is very important that planning permission be granted to allow turbines to be mounted above ridge height.

\section{Conclusions}

Wind flow within the urban environment is far from fully understood. Numerical results from this paper must be considered as very approximate, and only applicable to building arrangements similar to that modelled. It is, however, possible to reach some general conclusions.

Mean wind speeds at roof top height in the urban environment are much lower than wind atlas figures would suggest. A generic wind atlas such as that available for UK should be used with extreme caution when calculating energy yield for a roof-mounted wind turbine and may require a correction factor as outlined in this paper.

Different mounting positions are better suited to different prevailing wind situations. It is worth noting that the very centre of the roof rarely out-performs other mounting positions. The increased difficulty of mounting a turbine here means that it can normally be ruled out as a potential mounting point.

The wind is very strongly sheared at roof top height. This makes the height of the turbine mounting extremely important. If domestic turbines are to produce optimum yield, local authorities must grant planning permission for turbines to be mounted above the roof top ridge line. 
Potential Yield Of Small Building-Mounted Wind Turbines - Heath et al.

The wind speed-up seen over the ridge of an isolated building is quite significant, however, this effect is virtually absent for a house embedded within an array of surrounding houses.

Even when mounted above the ridge, the calculations detailed in this paper would suggest that the energy yield of a turbine on a typical house in an urban environment is likely to be low. Therefore, the economic viability of domestic wind turbines in a builtup urban environment needs to be carefully considered. The capacity factor may be more reasonable in some situations, e.g. on particularly tall buildings or isolated houses. Clearly, such buildings should be targeted first for installation of small wind turbines. It should be stressed that this paper has modelled one particular configuration of houses and further work is required to look at different configurations.

\section{Recommendations}

The methodology for estimating wind speeds given here needs some refinement. Methods need to be developed for estimating the parameters used by Macdonald's formulae, e.g. building densities, drag coefficients, etc., for building arrangements which are more complicated than arrays of cubes. The effects of vegetation within the urban area also need to be taken into account.

This paper has investigated only wind speeds, and has largely ignored turbulence in the wind flow. Flow close to buildings is likely to be highly turbulent, and this also needs to 
Potential Yield Of Small Building-Mounted Wind Turbines - Heath et al.

be studied for its effect on turbine performance. This may require more detailed LES modelling and high frequency wind speed data for validation.

Most research into urban wind flow has been conducted either in wind tunnels or computer simulations. There is a need for measured wind speed in the urban roof-top environment to provide validation for this and future work.

\section{References}

1. Tutar M and Oguz G. Large eddy simulation of wind flow around parallel buildings with varying configurations. Fluid Dynamics Research 2002; 31: 289-315.

2. Tutar M and Oguz G. Computational Modeling of Wind Flow Around a Group of Buildings. International Journal of Computational Fluid Dynamics 2004; 18: 651-670.

3. Zhang A, Gao C and Zhang L. Numerical simulation of the wind field around different building arrangements. Journal of Wind Engineering and Industrial Aerodynamics 2005; 93: 891-904.

4. MacDonald RW. Modelling the mean velocity profile in the urban canopy layer. Boundary-Layer Meteorology 2000; 97: 25-45.

5. Grimmond CSB and Oke TR. Aerodynamic properties of urban areas derived from analysis of surface form. Journal of Applied Meteorology 2000; 38: 1262-1292.

6. MacDonald RW, Griffiths RF and Hall DJ. An improved method for the estimation of surface roughness of obstacle arrays. Atmospheric Environment 1998; 32: 1857 1864. 
Potential Yield Of Small Building-Mounted Wind Turbines - Heath et al.

7. Burch SF, and Ravenscroft F. Computer modelling of the UK wind energy resource: overview report, ETSU WN7055, 1992.

8. Traci RM, Phillips GT and Patnaik PC. Developing a site selection methodology for wind energy conversion systems, DOE/ET/20280-3, 1978, prepared for the US

Department of Energy by Science Applications Incorporated, La Jolla, CA.

9. Mertens S. The energy yield of roof mounted wind turbines. Wind Engineering 2003; 27: 507-518.

10. Taylor PA and Lee RJ. Simple guidelines for estimating wind speed variations due to small scale topographical features. Climatological Bulletin 1984; 18: 3-32.

11. Launder BE and Spalding DB. Mathematical models of turbulence, Academic Press, New York, 1972.

12. Rhie CM and Chow WL. Numerical study of the turbulent flow past an airfoil with trailing edge separation. AIAA J1 1983; 21: 1527-1532.

13. Martinuzzi R and Tropea $\mathrm{C}$. The flow around surface-mounted, prismatic obstacles placed in a fully developed channel flow. Journal of Fluids Engineering 1993; 115: 8592.

14. CIBSE. Environmental Design CIBSE Guide A. CIBSE 1999; pp. 2-63, 2-64.

15. Renewable Devices Ltd. Swift Technical Information Pack 12005. 
Potential Yield Of Small Building-Mounted Wind Turbines - Heath et al.

\section{Figures}


Potential Yield Of Small Building-Mounted Wind Turbines - Heath et al.

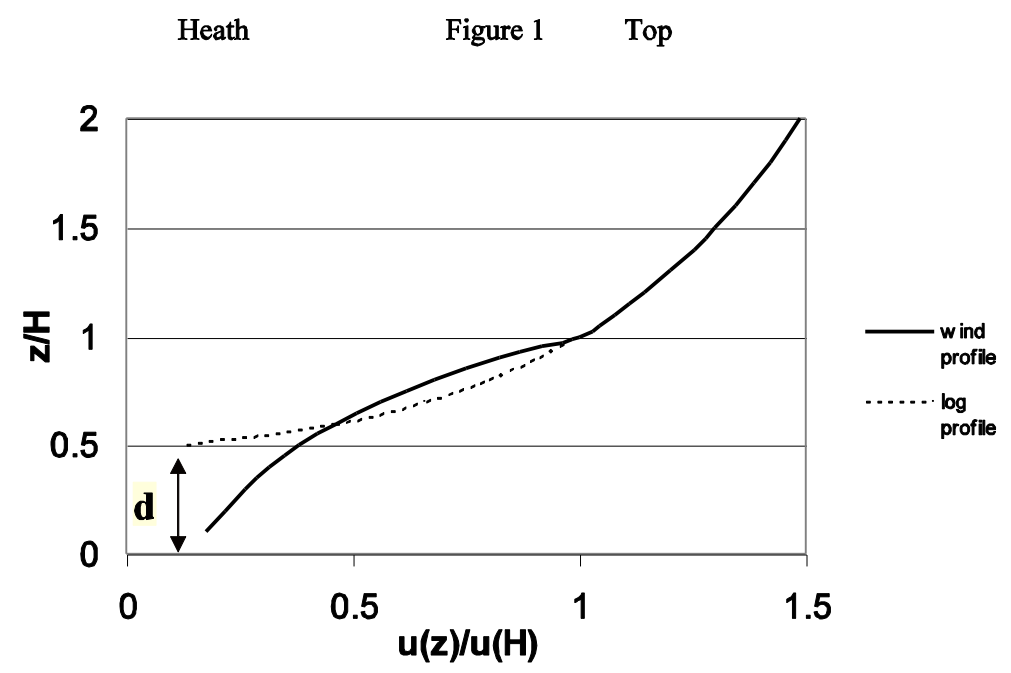

Figure 1: Normalised urban wind profile at a height $z$ above the ground, where $H$ is the building height and $d$ the effective displacement height. 
Potential Yield Of Small Building-Mounted Wind Turbines - Heath et al.

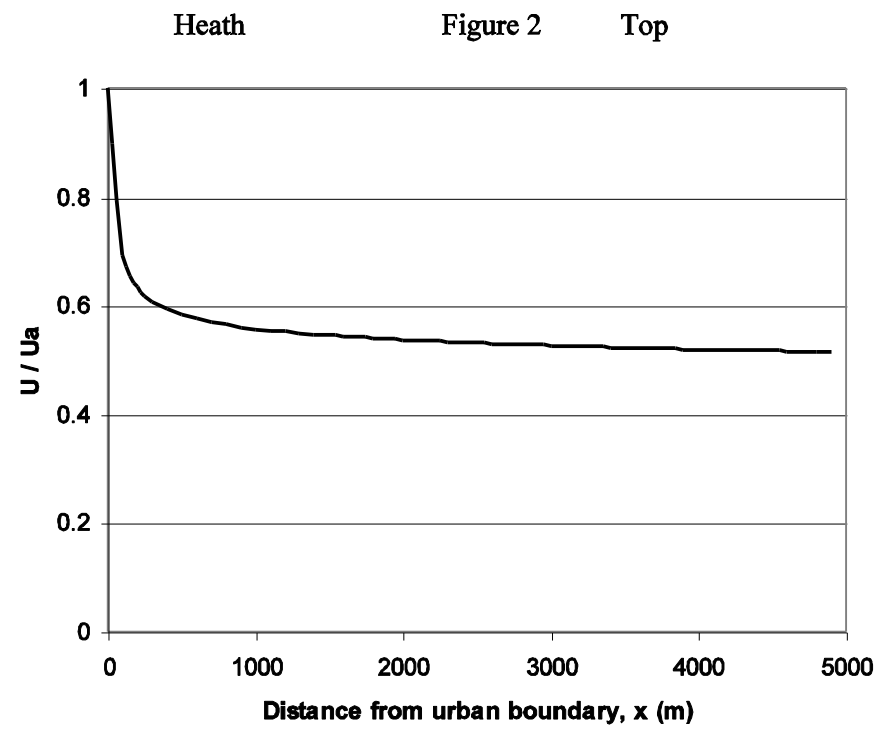

Figure 2: Adjustment of wind speed $U$ downstream of an urban boundary, at a height $z=10 \mathrm{~m}$ above the ground. 
Potential Yield Of Small Building-Mounted Wind Turbines - Heath et al.

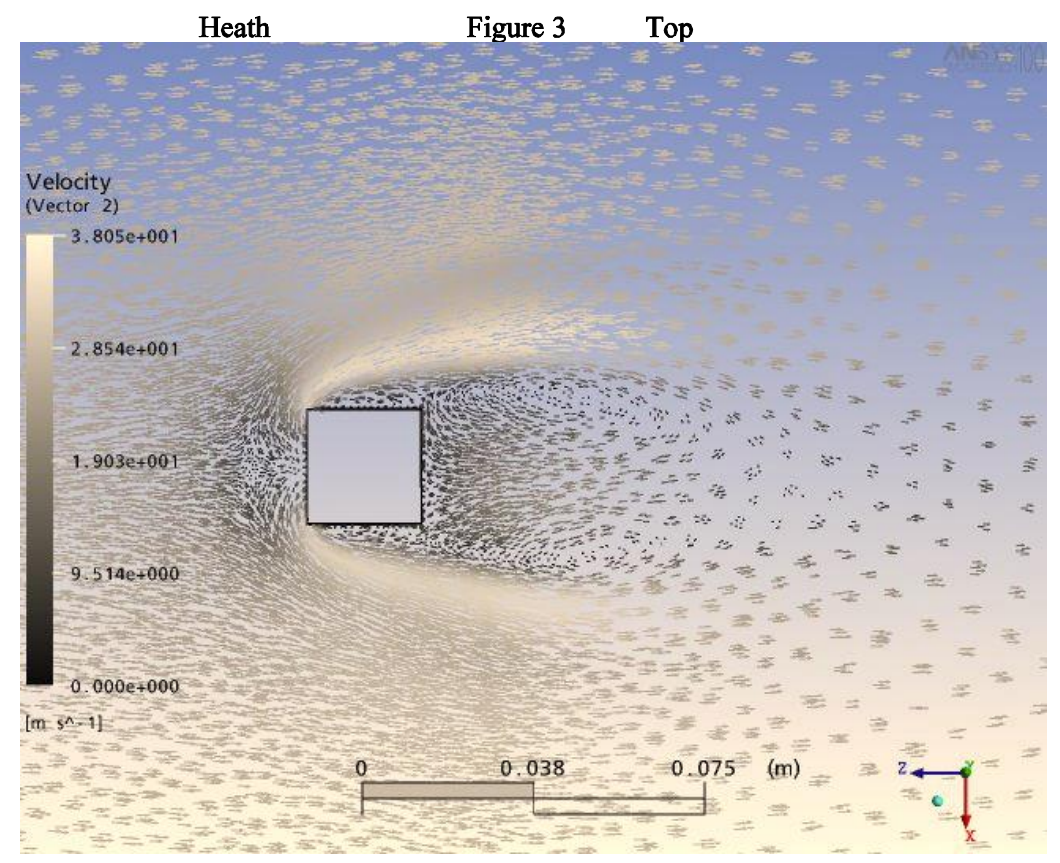

Figure 3: Flow pattern as seen from above around the test cube as simulated by the CFD model. 
Potential Yield Of Small Building-Mounted Wind Turbines - Heath et al.

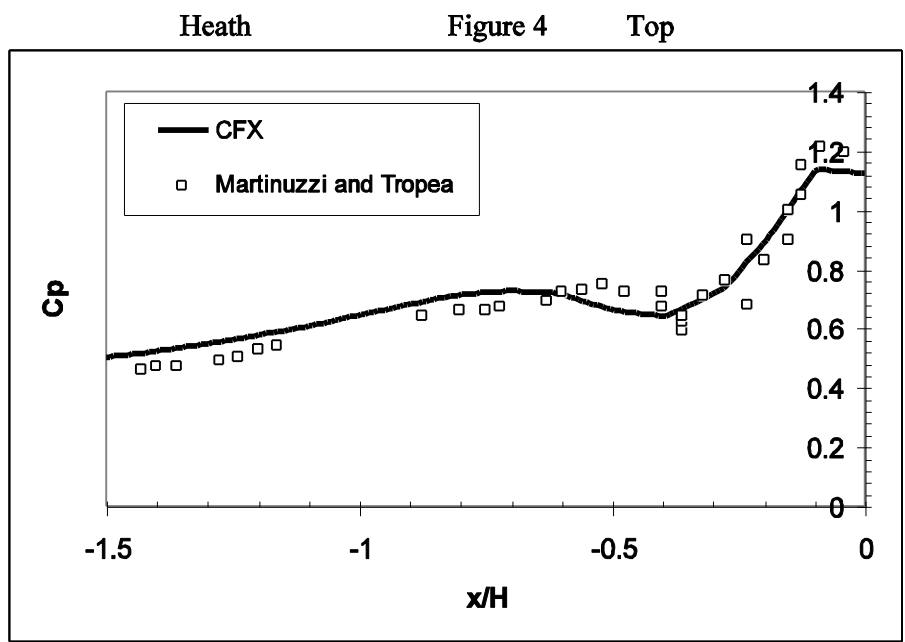

Figure 4: A comparison of the pressure coefficient, $\mathrm{Cp}$, upstream of the cube as predicted by the CFD model and measured in a wind tunnel along $z / H=0 . \operatorname{Re}=10^{5}$. 
Potential Yield Of Small Building-Mounted Wind Turbines - Heath et al.

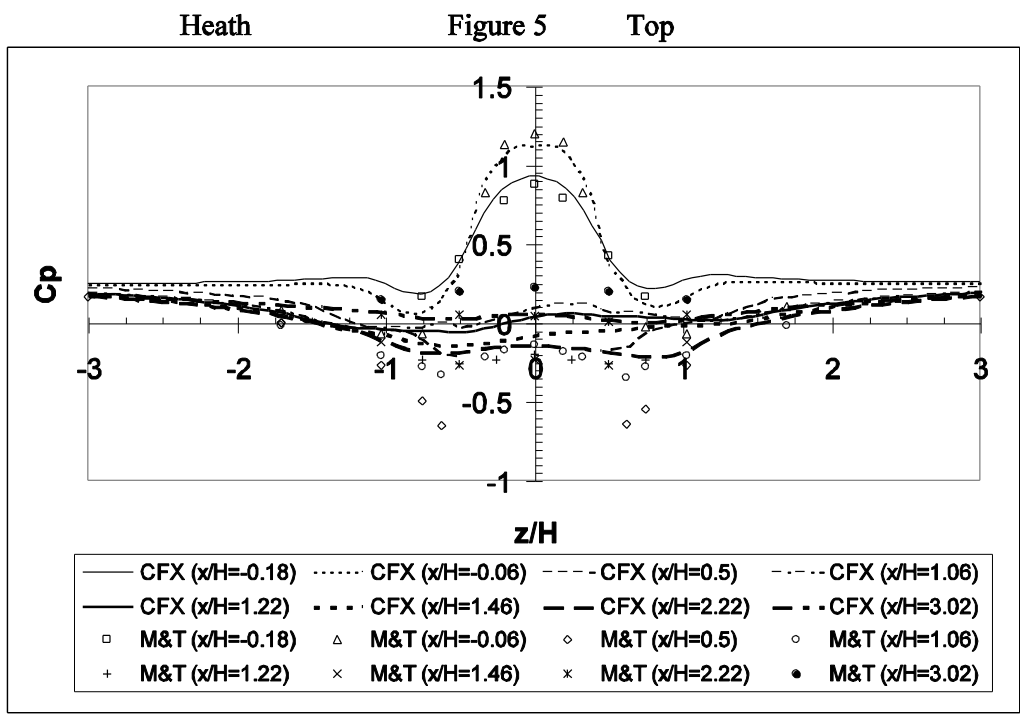

Figure 5: A comparison of the pressure coefficient, $\mathrm{Cp}$, around the cube as predicted by the CFD model and measured in a wind tunnel (M\&T). $R e=10^{5}$. 
Potential Yield Of Small Building-Mounted Wind Turbines - Heath et al.

Heath

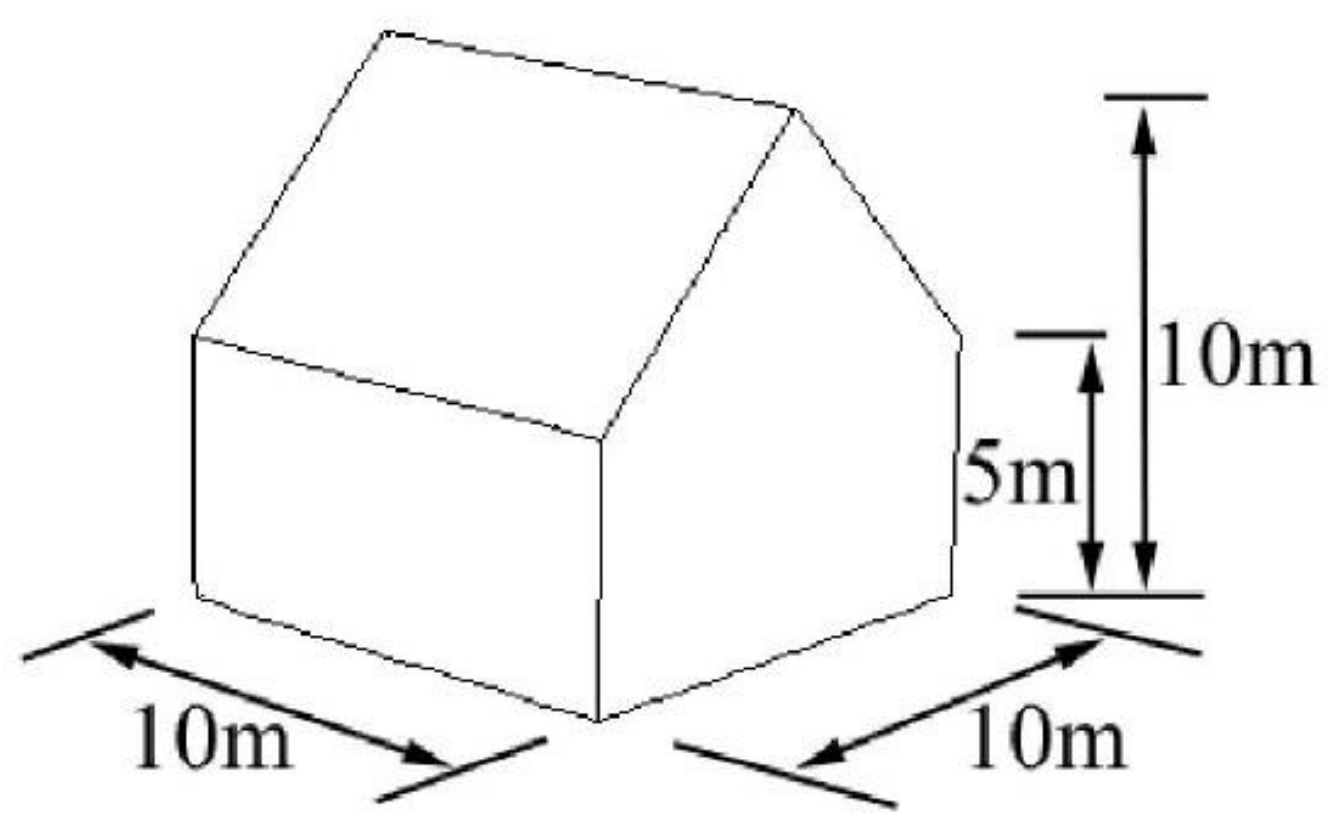

Figure 6: The 'typical' two-storey house used in the CFD wind flow modelling. 
Potential Yield Of Small Building-Mounted Wind Turbines - Heath et al.

Heath

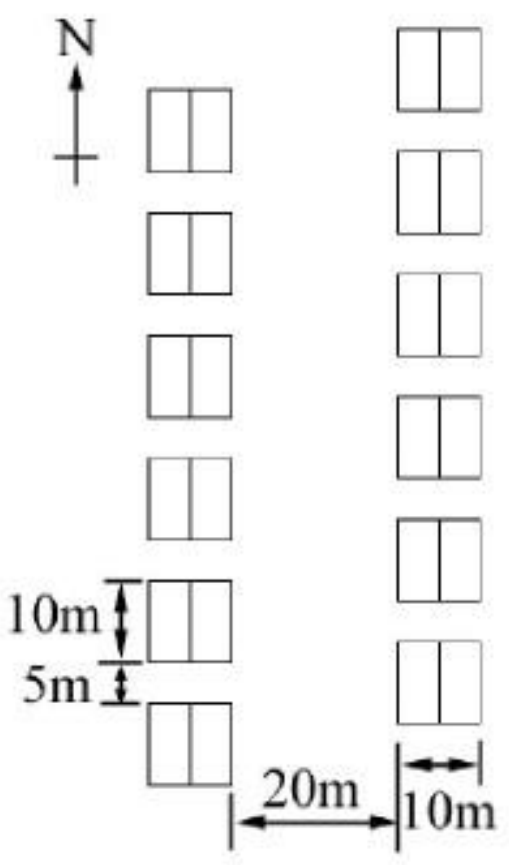

Figure 7 Top

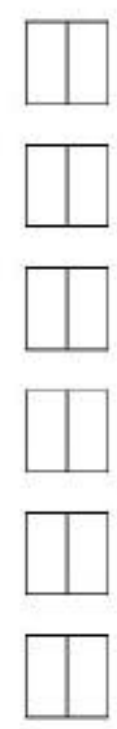

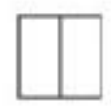
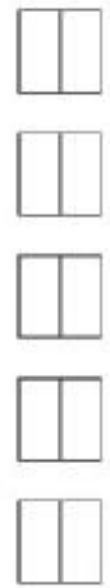

Figure 7: The building arrangement used to simulate streets of houses with the CFD model. 
Potential Yield Of Small Building-Mounted Wind Turbines - Heath et al.

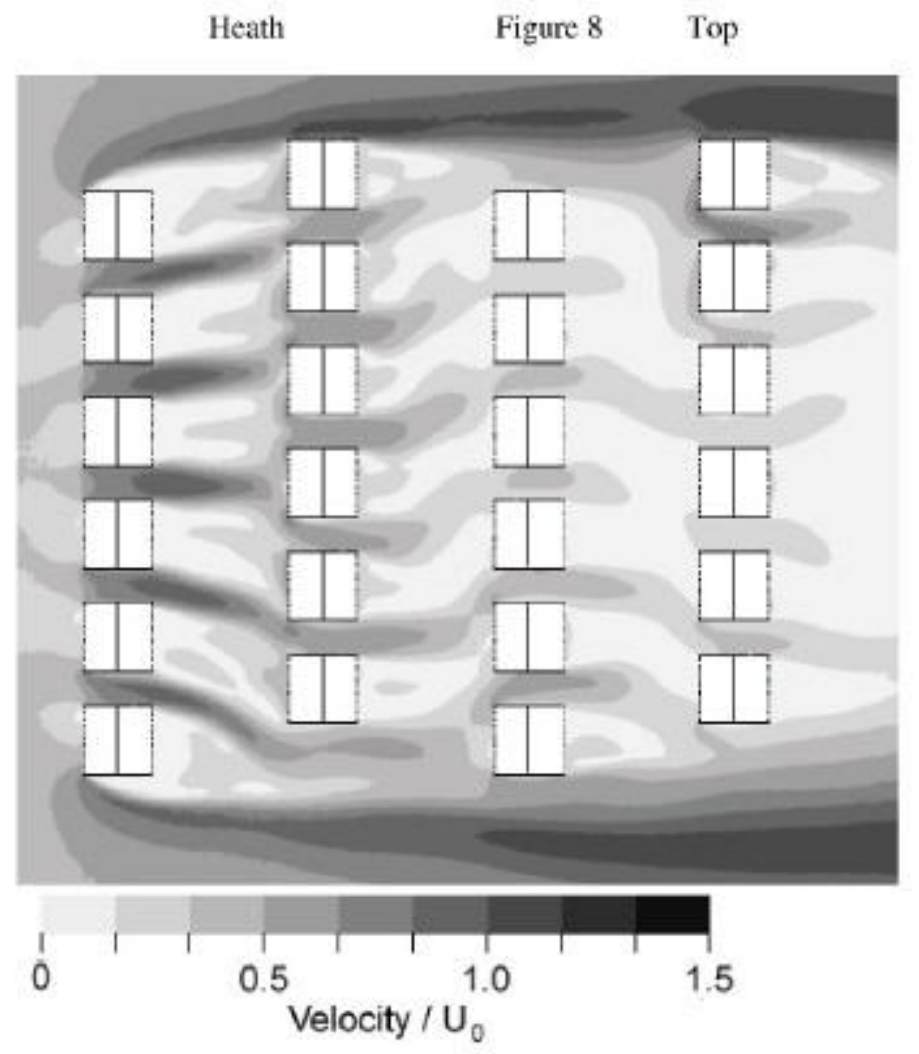

Figure 8: Normalised magnitude of the wind speed at $z / H=0.5$ within the building array for a westerly wind. 
Potential Yield Of Small Building-Mounted Wind Turbines - Heath et al.

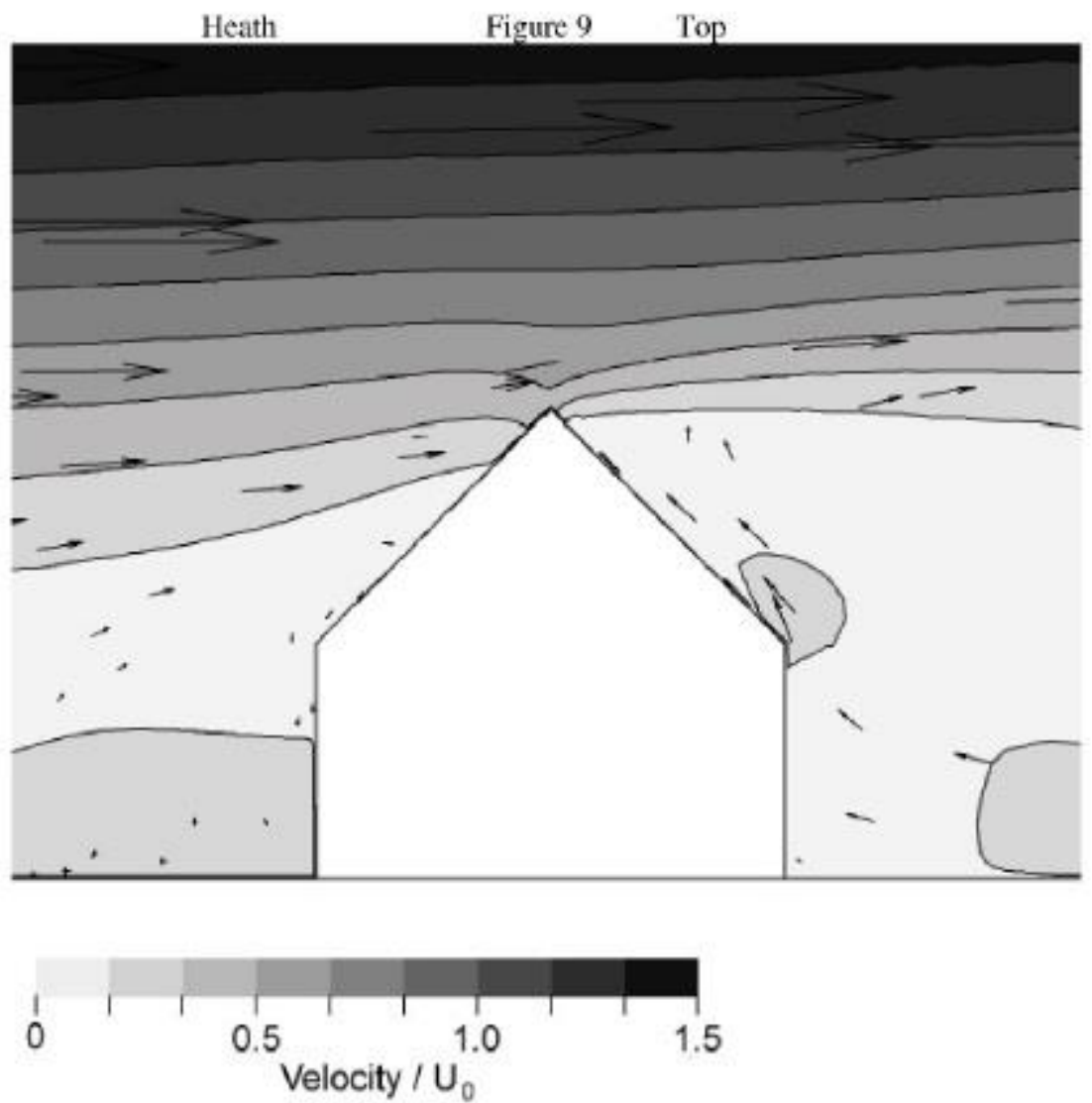

Figure 9: Wind velocity profile across a house in the middle of the most downwind row of houses within the building array. 
Potential Yield Of Small Building-Mounted Wind Turbines - Heath et al.

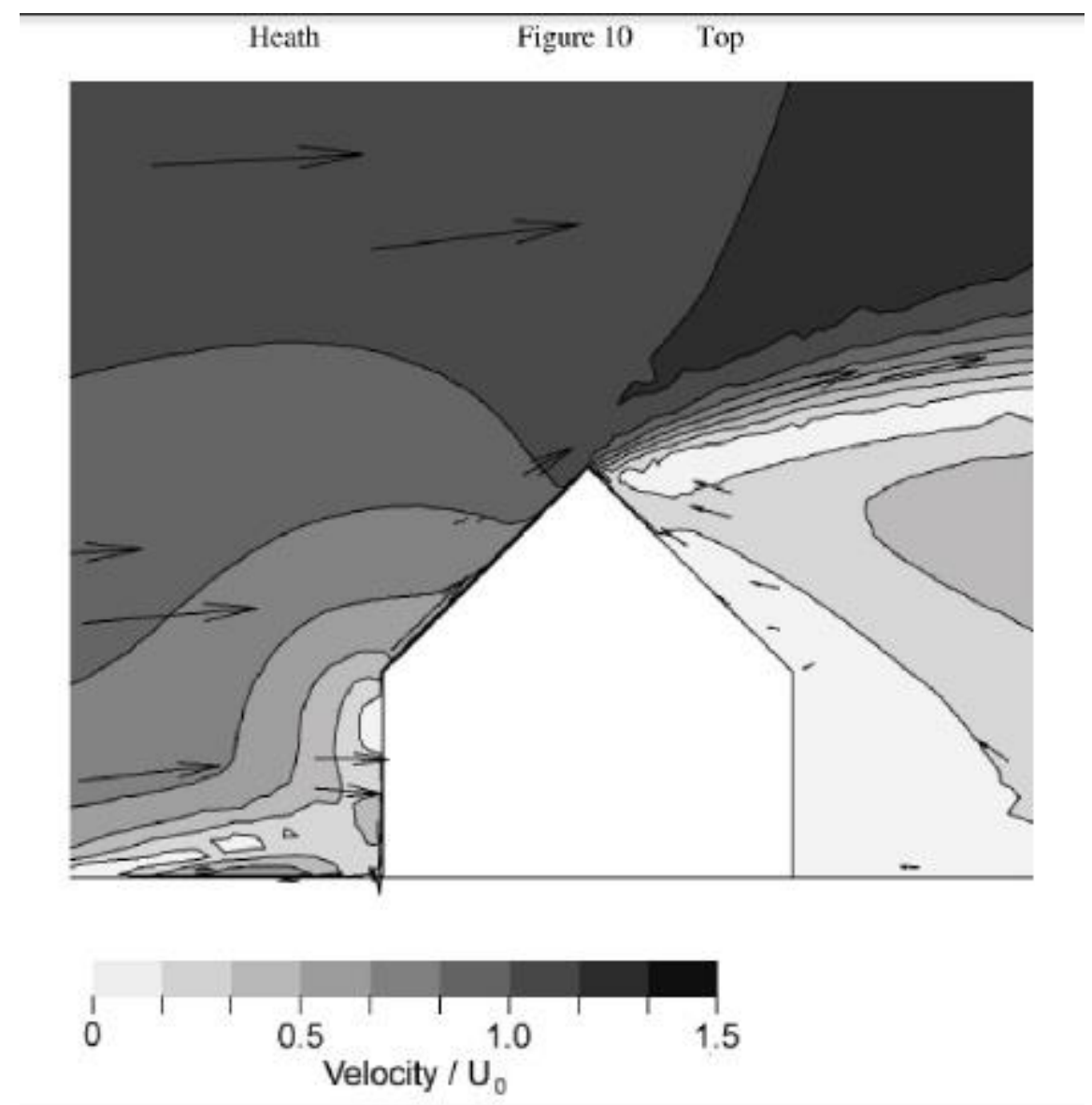

Figure 10: Wind velocity profile across an isolated house.
Heath
Figure 11 Top

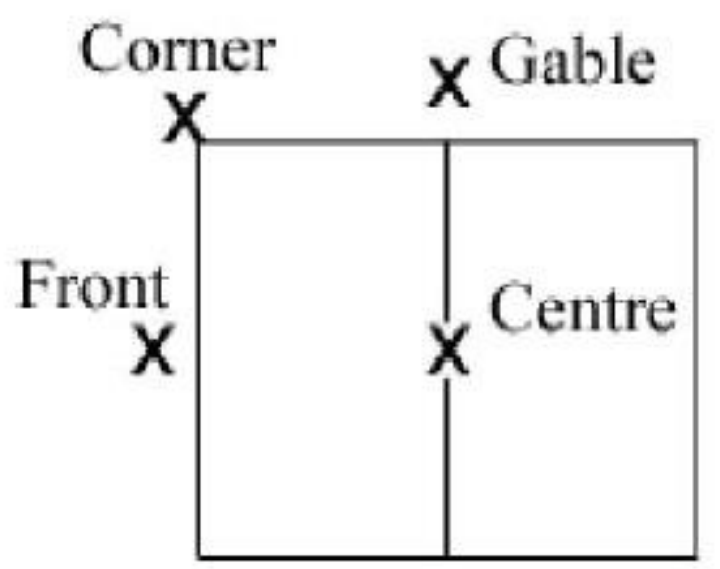

Figure 11: Plan view of a house showing potential turbine mounting points. 
Potential Yield Of Small Building-Mounted Wind Turbines - Heath et al.

Heath Figure 12a Top

\section{Front}

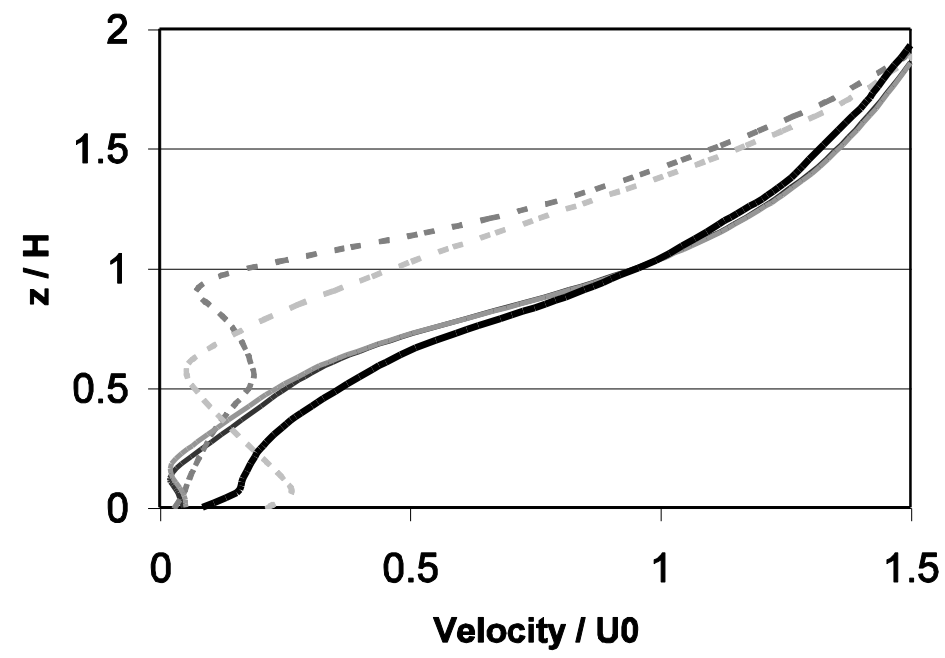

$\longrightarrow \mathbf{N}==-\mathbf{E} \longrightarrow \mathbf{S}=-=\mathbf{W} \longrightarrow$ Upstream 
Potential Yield Of Small Building-Mounted Wind Turbines - Heath et al.

Heath Figure 12b Top

Gable End

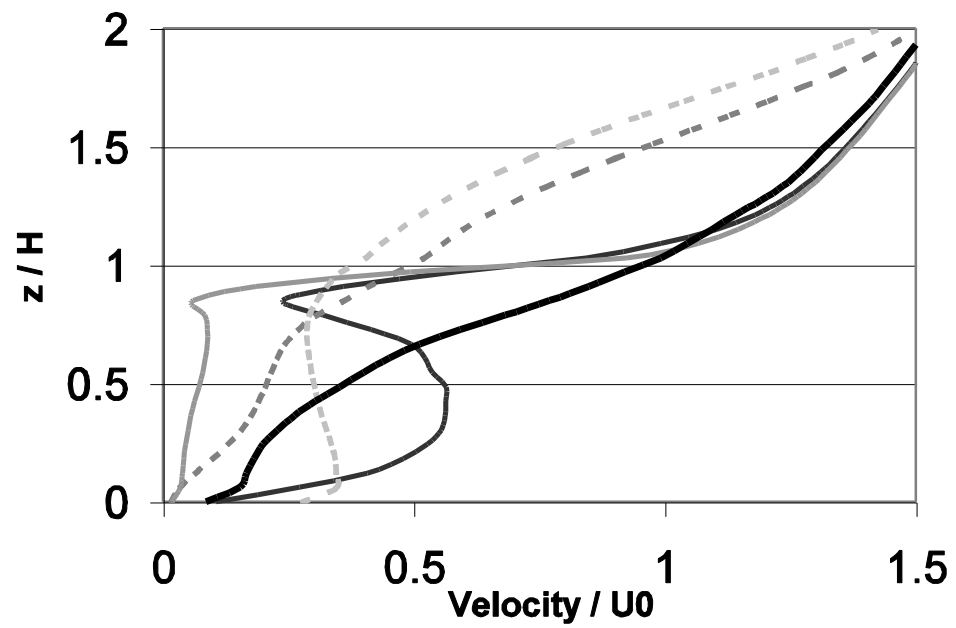

$\longrightarrow \mathbf{N}=--\mathbf{E} \longrightarrow \mathbf{S}=--\mathbf{W} \longrightarrow$ Upstream 
Potential Yield Of Small Building-Mounted Wind Turbines - Heath et al.

Heath Figure 12c Top

Corner

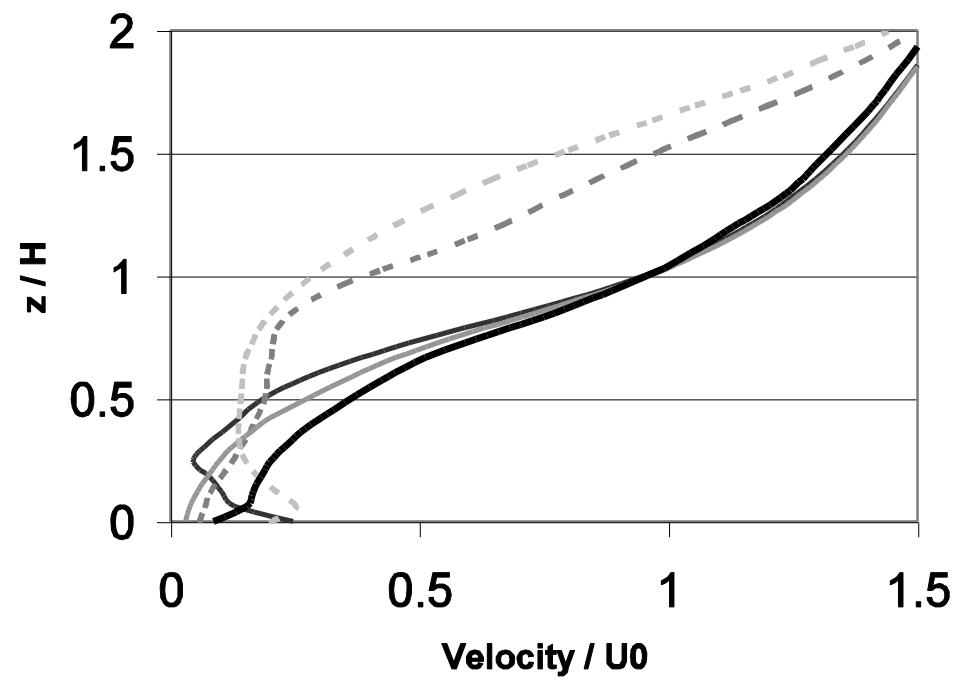

$-\mathbf{N}=-\cdot \mathbf{E} \longrightarrow \mathbf{S}-\cdots \mathbf{W} \longrightarrow$ Upstream 
Potential Yield Of Small Building-Mounted Wind Turbines - Heath et al.

Heath Figure 12d Top

Centre

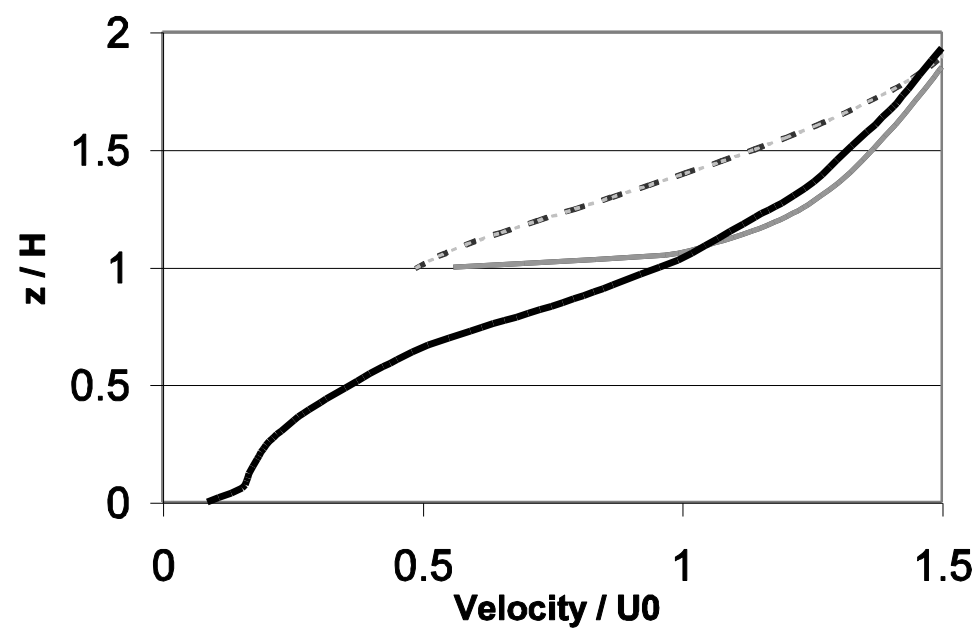

$\longrightarrow \mathbf{N}=-=-\mathbf{E} \longrightarrow \mathbf{S}==-\mathbf{W} \longrightarrow$ Upstream

Figure 12: Wind profiles at various mounting points: (a) front, (b) gable end, (c) corner and (d) centre. 
Potential Yield Of Small Building-Mounted Wind Turbines - Heath et al.

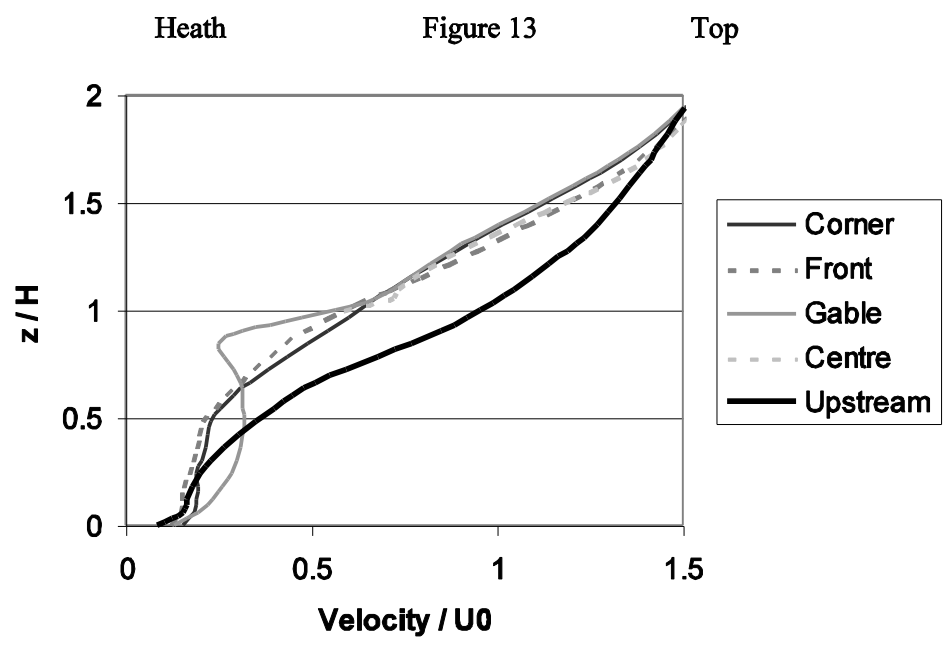

Figure 13: Mean wind profiles for all mounting points. 
Potential Yield Of Small Building-Mounted Wind Turbines - Heath et al.

This is the pre-peer reviewed version of the following article: Heath $M A$, Walshe $J$ D and Watson S J (2007). 'Estimating the potential yield of small buildingmounted wind turbines', Wind Energy 10 pp 271-287, which has been published in final form at http://onlinelibrary.wiley.com/doi/10.1002/we.222/abstract . 
Potential Yield Of Small Building-Mounted Wind Turbines - Heath et al.

\section{Tables}

\begin{tabular}{|c|c|c|c|}
\hline Wind & & Mounting $\mathrm{l}$ & ht, $z / H$ \\
\hline Direction & 0.8 & 1.0 & 1.3 \\
\hline $\mathrm{N}$ & $\begin{array}{l}\text { South corners } \\
l_{n}=0.6\end{array}$ & $\begin{array}{l}\text { South corners } \\
l_{n}=1.0\end{array}$ & $\begin{array}{l}\text { South gable or centre } \\
l_{n}=1.3\end{array}$ \\
\hline NE & $\begin{array}{l}\text { SE corner } \\
l_{n e}=0.6\end{array}$ & $\begin{array}{l}\text { SE corner } \\
l_{n e}=0.9\end{array}$ & $\begin{array}{l}\text { SE corner } \\
l_{n e}=1.1\end{array}$ \\
\hline $\mathrm{E}$ & $\begin{array}{l}\text { Gable ends } \\
l_{e}=0.3\end{array}$ & $\begin{array}{l}\text { East front } \\
l_{e}=0.5\end{array}$ & $\begin{array}{l}\text { East front or centre } \\
l_{e}=0.9\end{array}$ \\
\hline SE & $\begin{array}{l}\text { NE corner } \\
l_{s e}=0.6\end{array}$ & $\begin{array}{l}\text { NE corner } \\
l_{s e}=0.8\end{array}$ & $\begin{array}{l}\text { NE corner } \\
l_{s e}=1.1\end{array}$ \\
\hline$S$ & $\begin{array}{l}\text { North corners } \\
l_{s}=0.6\end{array}$ & $\begin{array}{l}\text { North corners } \\
l_{s}=1.0\end{array}$ & $\begin{array}{l}\text { North gable or centre } \\
l_{s}=1.3\end{array}$ \\
\hline SW & $\begin{array}{l}\text { NW corner } \\
l_{s w}=0.6\end{array}$ & $\begin{array}{l}\text { NW corner } \\
l_{s w}=0.8\end{array}$ & $\begin{array}{l}\text { NW corner } \\
l_{s w}=1.1\end{array}$ \\
\hline $\mathrm{W}$ & $\begin{array}{l}\text { Gable ends } \\
l_{w}=0.3\end{array}$ & $\begin{array}{l}\text { West front } \\
l_{w}=0.5\end{array}$ & $\begin{array}{l}\text { West front or centre } \\
l_{w}=0.9\end{array}$ \\
\hline NW & $\begin{array}{l}\text { SW corner } \\
l_{n w}=0.6\end{array}$ & $\begin{array}{l}\text { SW corner } \\
l_{n w}=0.8\end{array}$ & $\begin{array}{l}\text { SW corner } \\
l_{n w}=1.1\end{array}$ \\
\hline $\begin{array}{l}\text { Even } \\
\text { distribution }\end{array}$ & $\begin{array}{l}\text { Corners } \\
l_{\text {mean }}=0.5\end{array}$ & $\begin{array}{l}\text { Corners } \\
l_{\text {mean }}=0.6\end{array}$ & $\begin{array}{l}\text { Fronts } \\
l_{\text {mean }}=1.0\end{array}$ \\
\hline
\end{tabular}

Table 1: Optimum turbine position for prevailing winds. 
Potential Yield Of Small Building-Mounted Wind Turbines - Heath et al.

\begin{tabular}{|l|l|l|}
\hline Wind Direction & Below ridge & Above ridge \\
\hline $\mathrm{N}$ & South corners & South gable or centre \\
& $l_{n}=0.6$ & $l_{n}=1.3$ \\
\hline $\mathrm{NE}$ & SE corner & South gable \\
& $l_{n e}=0.6$ & $l_{n e}=1.0$ \\
\hline E & Gable ends & Centre \\
& $l_{e}=0.4$ & $l_{e}=0.9$ \\
\hline SE & NE corner & North gable \\
& $l_{s e}=0.6$ & $l_{s e}=1.0$ \\
\hline SW & North corners & North gable or centre \\
& $l_{s}=0.7$ & $l_{s}=1.3$ \\
\hline & NW corner & North gable \\
& $l_{s w}=0.6$ & $l_{\text {mean }}=0.5$ \\
\hline
\end{tabular}

Table 2: Optimum turbine locations assuming maximum mast length of $3 \mathrm{~m}$ and possible planning permission limit of ridge height. 
Potential Yield Of Small Building-Mounted Wind Turbines - Heath et al.

\begin{tabular}{|l|l|l|l|l|l|l|}
\hline Wind & $x$ & $U_{0}$ & $l$ & $\bar{U}$ & Freq. & $E$ \\
\hline $\mathrm{N}$ & 28000 & 2.3 & 1.2 & 2.8 & 10 & 79 \\
\hline $\mathrm{NE}$ & 38000 & 2.3 & 0.7 & 1.6 & 10 & 24 \\
\hline $\mathrm{E}$ & 46000 & 2.3 & 0.7 & 1.6 & 8 & 20 \\
\hline $\mathrm{SE}$ & 28000 & 2.3 & 1.0 & 2.3 & 7 & 38 \\
\hline $\mathrm{S}$ & 15000 & 2.4 & 1.3 & 3.1 & 16 & 159 \\
\hline $\mathrm{SW}$ & 4000 & 2.5 & 1.0 & 2.5 & 24 & 149 \\
\hline W & 4000 & 2.5 & 0.6 & 1.5 & 17 & 34 \\
\hline NW & 12000 & 2.4 & 0.7 & 1.7 & 7 & 17 \\
\hline Total annual energy yield & & & \\
\hline
\end{tabular}

Table 3: Energy yield calculation. 